\title{
ASSEXUALIDADE: OS DESAFIOS PARA O RECONHECIMENTO E ACEITAÇÃO SOCIAL
}

\author{
ASSEXUALITY: THE CHALLENGES FOR SOCIAL RECOGNITION AND \\ ACCEPTANCE
}

\author{
Camila Marcela Nemezio Lima ${ }^{1}$
}

\begin{abstract}
RESUMO: Esta pesquisa se propõe a elucidar quais são os desafios para o reconhecimento e aceitação social da assexualidade? Quanto ao objetivo geral, este foi investigar os desafios frente ao reconhecimento e aceitação social da assexualidade. No que se pretendem aos objetivos específicos estes foram: a) explicar a assexualidade, b) analisar uma perspectiva social da assexualidade e c) identificar os aspectos sociais que implicam no reconhecimento social da assexualidade.
\end{abstract}

Palavras-chave: Aceitação social. Perspectiva social. Sexualidade.

ABSTRACT: This research aims to elucidate what are the challenges for the recognition and social acceptance of asexuality? As for the general objective, this was to investigate the challenges facing the recognition and social acceptance of asexuality. Regarding the specific objectives, these were: a) to explain asexuality, b) to analyze a social perspective of asexuality and c) to identify the social aspects that imply the social recognition of asexuality.

Keywords: Social acceptance. Social perspective. Sexuality.

\section{INTRODUÇÃO}

O presente trabalho baseou-se no estudo do tema sobre a assexualidade diante da perspectiva social. Buscou-se compreender a visão desta no que se refere à emergência da identidade (as)sexual. Neste contexto, faz-se necessário explicitar acerca da sua definição, que se configura como uma orientação sexual, além da assexualidade ser caracterizada pelo baixo nível de desejo a prática sexual ou a ausência de atração sexual direcionada ao outro (SORIA, 2013). Esta se define como uma orientação sexual, pois segundo Crooks e Baur (2016) a assexualidade é compreendida como uma das múltiplas formas de manifestação da sexualidade humana, na qual ilustra a sua complexidade.

A assexualidade paulatinamente tem alcançado cada vez mais a sua visibilidade no contexto social. O fator primordial para a sua expansão que contribui para o seu conhecimento é através dos recursos midiáticos, entretanto esta crescente visibilidade e reivindicação desta, enquanto orientação

\footnotetext{
1 Graduanda em Psicologia pela Faculdade de Ciências Humanas de Olinda - FACHO. Email: camilamnemezio@gmail.com.
} 
sexual acabou por resultar em indiferenças no âmbito social, visto que, a assexualidade se diverge dos padrões heteronormativos impostos pela sociedade.

A partir desta breve explanação sobre o assunto, esta pesquisa se propôs a elucidar quais são os desafios para o reconhecimento e aceitação social da assexualidade? Quanto ao objetivo geral, este foi investigar os desafios frente ao reconhecimento e aceitação social da assexualidade. No que se referem aos objetivos específicos estes foram: a) explicar a assexualidade, b) analisar a perspectiva social da assexualidade e c) identificar os aspectos sociais que implicam no reconhecimento social da assexualidade.

Para tanto, utilizou-se na condução desta pesquisa o método de abordagem teórica de natureza qualitativa, posto que a assexualidade ainda se caracteriza como um assunto vigente e principalmente por se tratar de um contexto social em que há a relevância de integrar mais informações e fomentar novas perspectivas quanto ao assunto. Para a realização deste estudo fora utilizada também a pesquisa documental, realizada através da análise dos depoimentos presentes no veículo de comunicação da BBC News Brasil em uma matéria que explicita sobre a assexualidade. Esta teve a finalidade identificar fatores do contexto social que apontam para os desafios da emergência desta orientação sexual através da análise deste registro.

A partir de buscas referentes à temática da assexualidade, percebe-se um quantitativo escasso de bibliografia e pesquisas no que concerne a este campo, mas que, do mesmo modo é perceptível o quanto as pesquisas encontradas são materiais recentes, o que configura este assunto como vigente. Um blog encontrado na internet que se caracteriza como uma comunidade para os indivíduos que se identificam como assexuais, traz discussões pertinentes acerca da temática e se constitui como um dos primeiros registros datados sobre a assexualidade, intitulado de Asexual Visibility and Education Network (AVEN) que foi desenvolvido no ano de 20oI. Atualmente este blog foi evidenciado e referenciado como uma das principais fontes do assunto em pesquisas científicas.

A justificativa deste estudo se constitui a partir das crescentes informações relacionadas ao assunto que perpassam a contemporaneidade, contudo mesmo se tratando de um contexto atual é importante enfatizar que a assexualidade se faz presente desde antes de sua denominação. A partir do explicitado outro aspecto a ser ressaltado no que concerne aos objetivos deste estudo e que revela sua significância, se refere às implicações quanto ao reconhecimento desta identidade (as)sexual que acaba por ser restrita mesmo com seu manifesto. Percebe-se a partir disto que foi imprescindível a investigação neste aspecto, principalmente a partir do âmbito social que consistiu na compreensão deste fenômeno, além de atenuar as indiferenças quanto a esta singularidade. Outro ponto a ser elucidado é a importância da emergência desta identidade assexual em específico a denominação da assexualidade 


\section{Fundamentação teórica I.I A Assexualidade}

Neste capítulo serão explorados os conceitos e características da assexualidade, bem como sua consolidação enquanto orientação sexual.

A assexualidade pode ser compreendida pelo baixo nível ou a ausência de desejo pela prática sexual e ou da atração sexual (SORIA, 2013). Contudo, está também pode ser concebida como uma orientação sexual, visto que, membros de diversas comunidades de assexuais reivindicam o reconhecimento de sua orientação sexual, a qual é caracterizada pela ausência do desejo. Tal requerimento baseia-se no que há em comum a outras orientações sexuais, neste contexto, se os indivíduos acabam por estabelecer uma autoidentificação como assexuais, não seria este um fator de escolha, mas sim parte da identidade do sujeito (OLIVEIRA, 2012).

Entretanto, segundo Santos (2016), há aqueles que interpretam a assexualidade como uma forma de subjetividade que atrelada a uma circunstância particular envolvendo a sexualidade pode variar.

Outra concepção no que concerne à compreensão da assexualidade, temos Crooks e Baur (2016) os quais entendem a sexualidade como um fenômeno de caráter complexo que se manifesta de diferentes formas, a assexualidade nesta conjuntura, configura-se apenas como uma destas formas.

Scherrer (2008) em sua pesquisa referente à temática indagava aos participantes membros da comunidade Asexual Visibility and Education Network (AVEN), sobre a autocompreensão que apresentavam da assexualidade. $\mathrm{O}$ autor acabou por obter respostas abundantes e díspares, então constatou a partir dos dados que a ausência de atração e de desejo sexual era uma característica predominante na narrativa dos participantes, contudo a definição não era universal entre eles, além de considerar as dimensões românticas, isto é, o interesse romântico tal qual alguns assexuais experimentam.

Bogaert (2012), explicita que o assexual é aquele que não possui desejo sexual e devido a este fator não sente atração sexual, mas é também considerado assexual aquele que apresenta algum nível de desejo sexual, porém não consegue conectar-se ao desejo do outro. Neste contexto, a denominação assexual pode ser considerada mais ampla do que somente a ausência total de atração, entretanto os indivíduos que acabam por demonstrar pouco ou nenhum desejo para a prática sexual se autoidentificam também como assexuais. É importante enfatizar que estes podem possuir vínculos românticos, mas sem práticas eróticas. Outro aspecto a ser elucidado é que a identificação com a assexualidade não faz do indivíduo incapaz de ser estimulado sexualmente, além de que segundo Santos (2016, p.17) "o desejo e atração podem ser dissociados um do outro." Referindo-se às diversas 
formas de experiência assexual, estes não estão isentos de experienciar a excitação sexual, bem como podem ter práticas masturbatórias, além da possibilidade ou não de apresentarem comportamentos sexuais e sentirem ou não o desejo de possuir uma relação romântica (ANDREA; ROMAGNOLI, 2018).

Faz-se necessário relatar acerca da diferenciação no que se refere a orientação sexual e orientação romântica, na qual esta última se faz presente nas narrativas dos assexuais. Segundo Diamond (2008 apud ANDREA E ROMAGNOLI, 2018), a orientação sexual pode ser considerada como padrão de desejo sexual estável direcionados a indivíduos do sexo oposto ou do mesmo sexo. Neste contexto há uma amplitude atrelada à assexualidade, pois os indivíduos que se reconhecem como assexuais podem se identificar com as intituladas orientações românticas, na qual se caracteriza por uma atração romântica. $\mathrm{Na}$ assexualidade estas são descritas como heterorromântico, homorromânticos, bi-românticos, arromânticos, e dentre diversas outras denominações (ANDREA; ROMAGNOLI, 2018). Percebe-se a partir destes elementos, que a atração não apenas se restringe à atração sexual, bem como também há outras formas de atração existentes.

De acordo com Andrea e Romagnoli (op.cit.) a assexualidade possui diversas ramificações de identificação as quais são concernentes aos níveis de atração sexual que podem sentir. A Gray-A também intitulada de área cinza, corresponde aos indivíduos que experimentam a atração sexual, contudo em contextos específicos. Pode-se definir a Gray-A como uma atração sexual oscilante, isto é, estes podem apresentar atração sexual em determinados períodos, mas também podem ficar um tempo sem senti-la. Outra classificação que se encontra na área cinza é a demissexualidade, que segundo Scott e Dawson (2015), se caracteriza por indivíduos que apresentam atração sexual, entretanto apenas com outros dos quais possui algum vínculo afetivo.

A assexualidade em seu contexto histórico é um território pouco conhecido, contudo podese conceber a origem de seu termo a partir da comunidade virtual intitulada Asexual Visibility and Education Network (AVEN) desenvolvida em 2001 com a finalidade de promover a visibilidade assexual, definida como orientação sexual. Desde sua fundação há debates e discussões que fomentam na construção de conhecimentos no que se refere ao assunto, isto a partir dos relatos e vivências de indivíduos que se identificam com esta orientação. Compreende-se que a comunidade AVEN se estabelece na atualidade como a maior referência da assexualidade no mundo, visto que, possui membros não apenas no país em que fora fundada, isto é, nos Estados Unidos, mas bem como é concebida como referência em outros países (OLIVEIRA 2012). É pertinente enfatizar que a mesma impulsiona a criação de outras comunidades pelo mundo, inclusive no Brasil.

Segundo Neiva (2019) há a concepção advinda do social de que todos os seres humanos possuem desejo sexual, esta perspectiva é reverberada nas sociedades ocidentais a qual apenas de 
maneira esporádica é questionada. Ainda no que concerne a esta concepção, percebe-se a partir do senso comum cultural que a prática sexual é imutável, natural e trans-histórica. Neste contexto a assexualidade contribui para uma ampla compreensão da construção das sexualidades que, por vezes, de forma errônea acabam conceituadas em torno da mesma norma ou padrão heteronormativo, no qual se supõe que todos os indivíduos são heterossexuais, experimentam a atração sexual e desejam possuir uma relação afetivo-amorosa, neste sentido, percebe-se que as subjetividades, isto é, as singularidades dos indivíduos acabam suprimidas.

De acordo com Mello (2007 apud NEIVA, 2019) os padrões heterocêntricos constitui a perspectiva de casamento, família e parentalidade, entretanto estas concepções são questionadas através das lutas políticas realizadas por grupos marginalizados e não-hegemônicos. Faz-se necessário ressaltar que a constante inquietude que reside internamente na militância e nos movimentos políticos acaba por acarretar o risco da reprodução acrítica da heteronormatividade. Ainda conforme Mello (2007 apud NEIVA, 2019) na comunidade assexual é perceptível que existem pluralidades em seu interno, ou seja, não são todos os assexuais que não pleiteiam se casar e ou ter filhos, contudo este ainda é um fator que resulta no sofrimento de muitos assexuais, visto que, as concepções de conjugalidade e casamento ainda são definidas por categorias heterocentradas. Wittig (1992) afirma que a heterossexualidade não se caracteriza como algo concedido pela natureza, mas que há um pensamento propagado socialmente de que esta se configura desta forma.

De acordo com Neiva (2019) a heterossexualidade enquanto norma hegemônica dita e forma conceitos, leis, culturas e histórias, e esta, por sua vez, intitulada de "coerência natural” restringe o interesse sexual apenas direcionado ao sexo oposto, ou seja, este seria concebido como o interesse "natural", pois permite a possibilidade procriativa. Em tal perspectiva as relações afetivo-amorosas e sexuais marginalizadas seriam consideradas práticas "antinaturais".

Segundo Butler (2012) existe uma consolidação das normas no que concerne às sexualidades e às assexualidades que acaba por resultar em uma concepção fictícia de que sexo é concedido pela natureza, de modo como se houvesse identidades de gênero e sexuais estabelecidas. Tais ideias universalistas e essencialistas no que se refere à orientação sexual, ao gênero e sexualidade são padronizadas, contudo, a sexualidade humana conforme descrita neste capítulo é complexa e os limiares sexuais e assexuais são tênues.

\subsection{A concepção da sociedade acerca da assexualidade}

Sabe-se que a assexualidade tem alcançado cada vez mais visibilidade no contexto social, principalmente através da mídia que fora o fator primordial para o conhecimento da mesma (OLIVEIRA, 2012), contudo, através da crescente visibilidade que a comunidade assexual acabou 
constituindo, percebe-se indiferenças presentes no âmbito social quanto a expressão pública da assexualidade. Neste sentido, este o capítulo abordará algumas perspectivas decorrentes do social e concepções teóricas acerca do tema.

Segundo Carrigan (2012) em sua pesquisa sobre o tema, verificou uma série de narrativas advindas do social direcionadas aos indivíduos que se auto-identificam assexuais, tais como "você foi abusado quando criança?", "você apenas não conheceu a pessoa certa", ou "há algo de errado com seus hormônios?”, estas reações são bastante frequentes no que se refere ao assunto. Determinadas suposições possuem uma percepção de que houvera algum trauma infantil para que justifique a assexualidade em um indivíduo (BOGAERT, 2012).

Este fator de indiferença, por vezes, pode acarretar conflitos emocionais intrínsecos no sujeito que se identifica como assexual. Segundo Carrigan (2orI) tais reações patologizantes decorrentes do social influem em relatos de que os assexuais acabam por se sentirem "quebrados ou "danificados” com frequência. Compreende-se a partir destes aspectos que há muito trabalho a ser realizado com relação a todo o estigma vivenciado por aqueles que se identificam assexuais, embora seja evidente como afirmam Gazzola e Morrison (2012) que a literatura da atualidade aponta que as experiências assexuais são de fato, excluídas da compreensão social sobre sexualidade e as relações íntimas.

Fora mencionado acima acerca da concepção patologizante imposta a assexualidade, conforme Bogaert (2012) em seus estudos investigou a relação da assexualidade e o transtorno do desejo sexual hipoativo (TDSH) no qual se caracteriza pela ausência da libido. A junção de tais elementos fora de modo amplo, rejeitadas na literatura, e ainda enfatiza que a associação entre estas devem ser contestadas. Pois, segundo Prause e Graham (2007) a argumentação adotada neste contexto parte da observação de que as evidências disponíveis não apontam para um sofrimento ou dificuldades interpessoais necessárias para considerar um diagnóstico.

Outra concepção trazida por Bogaert (2010) considera que a intensa ausência de visibilidade cultural é um dos principais fatores para muitos justificarem a assexualidade como advinda de uma situação traumática ou de uma patologia física, a fim de encontrarem uma origem social óbvia para o assunto.

Pode-se considerar a concepção medicalizante no que se refere as sexualidades a partir do contexto socio-histórico, que de acordo com Azevedo (2017) a medicina acabou classificando as diferentes formas de prazeres, deste modo fora possível identificar as sexualidades que não convergiam aos padrões dominantes, isto é, a lógica heteronormativa. Neste sentido, estas sexualidades precisavam ser identificadas e expostas, pois era necessário obter o conhecimento sobre elas para que o controle fosse exercido efetivamente. 
Como afirma Foucault (2014) no intitulado dispositivo de sexualidade, as diversas sexualidades foram expostas e por conseguinte, dominadas pelo poder, que acabaram por regular as sexualidades singulares, além de controlar o sexo e restringi-lo ao leito conjugal. A disciplina imposta as sexualidades desenvolveu uma espécie de fábrica de corpos submissos, ou seja, corpos dóceis, que acaba por tornar a sexualidade passível de controle que corresponde a sujeição de determinadas regras (FOUCAULT, 2014).

Ainda conforme Foucault (2014) este, parte da reflexão de que a sexualidade deve ser compreendida como um dispositivo histórico de produção de categorias que emergiram a partir do século XVII no chamado mundo ocidental. Para Foucault (2014) a divisão das sexualidades era somente mais um meio de exercer o poder a fim de controlar o indivíduo, na qual conceberia a perspectiva de normalidade e anormalidade. A partir disto, percebe-se que houve uma segregação e por consequência a exclusão social daqueles que não se adequaram ao padrão ou não faziam parte desse reconhecimento social. Neste contexto Neiva (2018, p.4 - 5) afirma que:

[...] as assexualidades, ainda que se abdique de realizar práticas sexuais, se inserem em um conjunto de regras e de normas sociais mais amplas. Portanto, talvez seja válido pensar também o lugar das assexualidades enquanto produtoras de conhecimentos nessas relações de poder [...] inseridos/as no dispositivo de conhecimento sobre sexualidade, certamente assexuais também produzem socialmente uma certa noção de sexo/sexualidade e são invisibilizadas(os) porque não garantem o que as relações heterossexuais podem garantir: a reprodução, o parentesco, a organização social.

Segundo Hinderliter (2013) a grande finalidade da comunidade assexual é que a mesma seja aceita e concebida como parte de uma variação existente na sexualidade humana e não configurada como uma condição patológica a ser curada.

\section{Análise dos dados}

\section{I Os desafios sociais para o reconhecimento da identidade assexual}

Neste capítulo serão explorados os fatores presentes no social que implicam no reconhecimento e aceitação da assexualidade configurada enquanto uma identidade (as)sexual. Serão também abordados e analisados neste capítulo os depoimentos de indivíduos que se identificam assexuais.

Segundo Munárriz (2010 apud SANTOS, 2016), os indivíduos que se identificam como assexuais, concebem-se como diferentes e estigmatizados pela sociedade, neste contexto, sentem-se rejeitados e vítimas da opressão social. Conforme Santos (2016, p.44) expressa, "isso acontece porque a assexualidade não é entendida totalmente, dando margem à várias interpretações." Contudo, devese refletir que, por vezes, mesmo com o acesso preciso no que concerne ao assunto há uma resistência 
quanto a aceitação da assexualidade, bem como as demais sexualidades existentes que se diferem da heteronormatividade, estes aspectos levam a considerar a existência de fatores na sociedade que contribuem para a indiferença.

De acordo com Maclnnis e Hodson (2012 apud SANTOS, 2016) enquanto a assexualidade estava atrelada às patologias, um cenário que até pouco tempo se fazia presente, esta não era concebida como uma manifestação sexual saudável, bem como não se configurava como uma orientação sexual, enquanto esta era percebida de modo patológico, era também confundida pelo social com a prática do celibato, na qual consiste em abdicar do matrimónio e do exercício da prática sexual para fins religiosos, desde modo, esta era aceitável a determinados padrões de normalidade da sociedade.

A partir da emergência da assexualidade, a concepção de normalidade desta relacionada ao celibato pelo social fora contestada devido aos movimentos da comunidade assexual pelo seu reconhecimento como orientação sexual. A partir deste fator, houve a fragmentação da percepção de que a assexualidade estaria elencada a práticas espirituais e/ou religiosas. Neste movimento o assexual também fora apreendido por outras orientações sexuais, isto é, os heterossexuais e homossexuais se referiam aos mesmos como indivíduos atípicos, estranhos e pouco humanos, isto deve-se ao fato de que ambas as orientações estão vinculadas a atração e ao desejo pela prática sexual, e a assexualidade se caracteriza pela ausência destes elementos (SANTOS, 2016).

A tendência em “desumanizar” esses grupos são advindas da ideia de que todos os indivíduos são norteados por uma bússola instintiva conhecida como "natureza humana" e que os grupos diferentes do padrão sexualizado são vistos como desviantes ou "máquinas". (SANTOS, 2016, p. 45, grifo do autor)

Entretanto, segundo Rozenthal (2018) a luz da psicanálise a assexualidade acompanha seu prefixo negativo referente ao não desejo ou a não prática sexual, neste contexto, esta estaria configurada pela ausência do desejo. Contudo, para o assexual há investimentos subjetivos desejantes, ou seja, inconscientemente este se associa às características que foram conceituadas e inseridas a assexualidade pelo social e deseja consolidá-la como identidade assexual, neste contexto, conceder ao eu, sua identidade (as) sexual.

A partir disto, a assexualidade é compreendida como a qualidade dos sujeitos que se identificam como assexuais, neste aspecto, ao considerar-se e unir-se as características que se dirigem a uma sexualidade, estes acabam por corresponder a um conjunto genérico no qual pertence à sociedade, assim como os que se identificam heterossexuais e homossexuais, neste sentido, a identidade assexual representa subjetivamente a um catálogo de atributos genéricos dos quais pertencem ao eu (ROZENTHAL, 2018). 
Ainda conforme Rozenthal (2018), pode-se perceber que a assexualidade ainda implica no desejo, neste contexto, a escolha de representação do objeto do desejo assexual pode ser considerada o não exercício da prática sexual, e este fator não a torna menos objeto de prazer. Neste sentido, a procura pelo não exercício sexual se torna equivalente ao desejo que está presente nos demais grupos sexuais genéricos, este desejo concerne ao reconhecimento social dos direitos à assexualidade e a preservação de uma identidade e integridade do eu cujo é ameaçada pelos ideais sociais, que segundo Rozenthal (2018 p.I16) "sofremos de dissonância cognitiva entre o que reconhecemos ser eu e o que a sociedade nos impele a ser."

Deve-se refletir no que se refere às indiferenças, aos estigmas e o ato da não aceitação direcionados à assexualidade advindos da sociedade como uma forma de opressão social e não apenas disto, mas também de repressão sexual, visto que esta apreende-se como uma das formas da sexualidade humana, neste sentido, configurada nas conjunturas atuais como orientação sexual (CROOKS; BAUR, 2016). A repressão sexual como expressa Chauí (1984), é um fenômeno arcaico, mas no que se trata do conceito de repressão sexual este é concebido como vigente. A mesma retrata sobre o significado da palavra repressão que está atrelado ao verbo reprimir, este consiste em assegurar ou interromper um movimento ou uma ação, quer por imposição de um castigo, quer pela punição, ou ameaça, sentimento de desagrado que acaba por acarretar extinção de uma concepção, afeto ou prática. Estes fatores, concernem a aspectos da repressão que se apresentam de formas perceptíveis ou imperceptíveis.

A partir dos termos supracitados é notório que os mesmos evidenciam a ideia de impedir algo ou alguém que estava em uma direção não aceita. De acordo com Chauí (1984) há ainda a existência de operações psíquicas que internalizam a repressão enquanto um aspecto social. $\mathrm{O}$ ato da repressão não é apenas uma imposição, mas um processo de interiorização das proibições advindas do externo que se transformam em interdições internas, isto é, ocorrem conscientemente e inconsciente, que são vivenciadas de formas desagradáveis. Estes fatores, no que lhe concerne, conduzem à auto-repressão.

Costuma-se dizer que a repressão perfeita é aquela que já não é sentida como tal, isto é, aquela que se realiza como auto-repressão graças à interiorização dos códigos de permissão, proibição e punição de nossa sociedade. (CHAUÍ, 1984, p. 12)

A partir do estudo teórico realizado acima referente aos desafios presentes no social para o reconhecimento e a aceitação da assexualidade como orientação sexual, com base na pesquisa documental, serão analisados depoimentos retirados de um veículo de comunicação realizado pela BBC News Brasil (2018) de indivíduos que se identificam assexuais.

Entendi que a atração que sinto pelas pessoas está longe de ser sexual. Gosto de estar com elas, mas não quero ser tocada. Hoje, entendo que sempre quis 
um relacionamento por pura pressão social. Não sinto falta disso e me sinto muito feliz sozinha. Meus amigos e minha família são companhias suficientes.” (N., idade não declarada)

Uma amiga falou sobre o assunto em uma brincadeira e me despertou curiosidade. Encontrei um blog sobre o tema e me identifiquei com o que estava escrito. Foi muito tranquilo me aceitar como assexual. No fundo, me senti livre ao ver que havia pessoas iguais a mim. (J.A., 23 anos)

Eu conhecia sobre a assexualidade e tinha lido sobre o assunto, mas acreditava que se restringia àqueles que não se interessam por sexo em hipótese alguma. Anos depois, fiz novos estudos e descobri a área cinza, que é onde me encontro. Foi um processo longo, mas que me trouxe tranquilidade e paz. Mas nem todas as pessoas com quem eu criar esse vínculo irão me despertar atração sexual. No meu caso, especificamente, não precisa ser um elo romântico para que eu desenvolva essa atração, mas esse afeto precisa ser muito forte para que me desperte algo relacionado a sexo. Consigo contar em uma mão o número de pessoas por quem já me senti atraída sexualmente." (C.P, 24 anos)

A partir destes depoimentos, verifica-se além do conceito que traz a assexualidade as suas pluralidades existentes, isto é, suas variações, pois de acordo com Andrea e Romagnoli (2018) a assexualidade possui diversas ramificações de identificação as quais são concernentes aos níveis de atração sexual que podem sentir. A Gray-A (área cinza), está relacionada a indivíduos que experimentam a atração sexual, contudo em contextos específicos. Outra classificação que se encontra na área cinza é a demissexualidade, que segundo Scott e Dawson (2015), se caracteriza por indivíduos que apresentam atração sexual, entretanto apenas com outros dos quais possui algum vínculo afetivo.

Outro aspecto a ser elucidado é a importância da auto-compreensão no que se refere a própria identidade (as)sexual, bem como a relevância da assexualidade como uma das formas de expressão da sexualidade humana, ou seja, uma orientação sexual, pois uma vez que esta se estabelece como existente acaba por conceder aos indivíduos que não se identificam com outras formas de sexualidades que estes estabeleçam uma identificação de acordo com suas representações subjetivas do eu. Este aspecto, promove ao sujeito a ideia e o estado de pertencente a estrutura social e não, de modo, a sentir-se deslocado da mesma.

Eu já havia tido namoradas, mas nunca vi no sexo tudo aquilo que meus amigos falavam. Cheguei a questionar minha orientação sexual e também procurei ajuda médica, para uma possível reposição hormonal. Mas nada disso me trouxe respostas definitivas. Um tempo depois, quando eu tinha 17 anos, li um artigo sobre a assexualidade e me identifiquei bastante. Até então, eu havia tido relações sexuais com minhas ex-namoradas, mas costumava fazer isso para agradá-las. Quando me descobri, percebi que não valia a pena manter relacionamentos assim, porque isso me magoava. (E.C, 27 anos) 
Quando contei para a minha melhor amiga, ela me perguntou se havia tratamento para isso e disse que eu não poderia afirmar isso, porque nenhum médico tinha me diagnosticado assim. Isso me fez sentir uma pessoa doente. (A., 27 anos)

Brigávamos com frequência, porque eu não queria transar. Eles diziam que eu era falsa, que não os amava, por não ter atração sexual. Era complicado e eu acabava fazendo sexo. (L., 2I anos)

Conforme fora explorado no capítulo sobre as concepções sociais acerca da assexualidade, verifica-se através dos relatos, a perspectiva patologizante e medicalizante. A concepção patologizante, por norma, é associada ao transtorno do desejo sexual hipoativo (TDSH) que se caracteriza pela ausência da libido, entretanto é imprescindível ressaltar que a associação da assexualidade com o TDSH foram rejeitadas, pois, para se classificar como patológica se faz necessário existir um sofrimento por parte do indivíduo. Neste sentido, quando não há o interesse pela prática sexual e este aspecto não afeta a qualidade de vida do sujeito esta não se configura como disfuncional.

Muitas pessoas acreditam que assexuais não sofrem preconceitos, o que é uma tolice. Vivemos em uma sociedade na qual o sexo ainda representa sucesso e poder. Somos constantemente ensinados que só podemos nos sentir valorizados ao termos alguém, ao sermos desejados. É clara a existência de uma estrutura social que, com muita facilidade, reproduz preconceitos contra os assexuais. Durante anos, me senti uma pessoa quebrada. Uma das piores coisas era não encontrar quem pudesse me ajudar a entender o que eu sentia. Acho que muito do sofrimento que assexuais relatam sentir em suas vidas é culpa da falta de conhecimento e visibilidade sobre a assexualidade. (W.M., idade não declarada)

Pelos estudos que faço sobre a assexualidade, acho plausível a inclusão dela, na sigla LGBT, porque é um aspecto de identificação da pessoa, de ordem afetiva ou sexual. Não podemos ignorar essa orientação. Os assexuais também devem ser reconhecidos. Não incluí-los, para mim, é uma invisibilidade contra esse grupo. (B.R., idade não declarada)

Sabe-se que há reações indiferentes advindas do social que acabam por influir em relatos de que os assexuais se sentem "quebrados ou "danificados", conforme também fora elucidado em um capítulo anterior. Contudo, tais reações do social acabam por resultar em conflitos emocionais intrínsecos no sujeito que se identifica como assexual, este fator fora bem ilustrado através do presente depoimento. Outro elemento a ser destacado nas narrativas são de fato as experiências assexuais que acabam por ser, muitas vezes, excluídas da compreensão social no que concerne a sexualidade, as formas relacionais e de atração (GAZZOLA; MORRISON, 2012). 


\section{Resultados e discussões}

Conforme fora explicitado há a constante reivindicação pelo reconhecimento da assexualidade como uma orientação sexual, mesmo esta de forma a se caracterizar pelo baixo nível ou a ausência do desejo pela prática sexual. Entretanto, como fora demonstrado no estudo teórico, a assexualidade mesmo acompanhada de seu prefixo negativo não a torna menos sexual que as outras pluralidades sexuais existentes, visto que, simplificadamente a sexualidade é concebida como um fenômeno complexo que se manifesta de diferentes formas através do desejo, isto é, pode-se considerar como sexual tudo aquilo que desperta prazer ou traz satisfação ao sujeito (ROZENTHAL, 2018).

Costuma ser frequente a concepção de que os assexuais não enfrentam indiferenças, discriminações ou opressões. Entretanto, segundo Borgogna et.al (2018) a exclusão e o não reconhecimento de experiências assexuais acabam por acarretar taxas mais elevadas de retraimento social, problemas interpessoais, e até mesmo, tentativas de suicídio enquanto comparada as outras orientações sexuais. Neste sentido, percebe-se que tais indiferenças decorrentes do social acabam por resultar no sofrimento emocional, visto que, muitos assexuais se distanciam do mundo devido a não aceitação por parte do social e a imposição de normas ou padrões heteronormativos.

Como fora explorado ao longo deste do estudo, a ausência ou o baixo nível de atração sexual fora por muito tempo, concebida como patológica. Contudo, a assexualidade enquanto orientação sexual não se configura como advinda de uma ordem patológica, nem deve ser compreendida como resultado de um trauma ou como consequência de problemas hormonais (BOGAERT, 2012). Faz-se necessário ressaltar que um dos grandes movimentos da comunidade assexual fora a despatologização e para que esta não seja confundida com o Transtorno de Desejo Sexual Hipoativo (TDSH).

De acordo com o que foi exposto, pode-se afirmar que a imposição de um padrão sexual presente na estrutura social acaba por ser gerador de sofrimento emocional nos indivíduos que não correspondem ao determinado padrão, este fator não apenas está direcionado a assexualidade, bem como inclui as demais sexualidades. Contudo, na assexualidade além do enfrentamento da norma sexual imposta, há outros desafios quanto ao seu reconhecimento como uma orientação sexual, e estes, estão presentes desde a repressão das sexualidades, na qual, resulta nas concepções patologizantes e medicalizantes, desde também, na compreensão do senso-comum advinda de uma ordem social de que a sexualidade está restrita ao ato sexual, sem assim, considerar sua complexidade. Outro aspecto a ser elucidado, é que a assexualidade não poderia circunscrever sua existência sem ser aceita a não ser que esta estivesse relacionada ao celibato ou a qualquer outro viés regulatório. 


\section{Considerações finais}

Ao longo da realização deste estudo buscou-se refletir acerca da assexualidade e sociedade, objetivando a compreensão das implicações contidas no social para o reconhecimento e a aceitação da assexualidade como orientação sexual, visto que há a reinvindicação desta como uma identidade (as)sexual e, como fora apresentado em tela, no social há a presença de mecanismos de controles sobre o corpo que influem na regulação das sexualidades que se divergem do padrão heteronormativo, sendo este, um dos diversos fatores que implicam na aceitação. Conforme também fora explorado existem outros aspectos que acabam por dificultar no reconhecimento da assexualidade como uma orientação sexual, quer seja esta pela ausência de informações adequadas sobre o assunto, quer seja por confundi-la a uma prática espiritualista atrelada a religião, dentre outros fatores.

Percebeu-se através destes aspectos os empecilhos enfrentados pelos assexuais quanto as reivindicações pelo seu reconhecimento. Neste sentido, foram perceptíveis que muito dos discursos e concepções da sociedade direcionada aos assexuais reverberam nestes como sofrimento psíquico, posto que os indivíduos que se identificam como assexuais acabam por entrar em dissonância com aquilo que é imposto socialmente e com seus próprios ideais subjetivos que, neste sentido, entendese como sua identidade (as)sexual.

Pode-se considerar que há muito a ser refletido e estudado acerca da temática abordada com a finalidade de fomentar o conhecimento sobre esta, além de fortificar a assexualidade como uma orientação sexual, visto que a mesma está configurada como apenas uma das diversas formas de expressões da sexualidade humana.

\section{Referências}

ANDREA, Luigi Silvino D'; ROMAGNOLI, Roberta Carvalho. DESLOCANDO SOBRE O ARCO-ÍRIS COM TONALIDADES CINZA E PRETO: assexualidades em trânsito. Ártemis, Minas Gerais, v. XXV, ed. I, p. 219-239, 2018. Disponível ettps://periodicos.ufpb.br/index.php/ /view/36065. Acesso em: is jun. 2020.

AZEVEDO, Thiago Augusto Galeão de. Poder, verdade e sexo: a padronização de formas de vida pela criação de categorias sexuais, à luz da teoria de Michel Foucault. Sapere aude, Belo Horizonte, v. 8 , n. 15,2017 .

BBC News, Brasil. Quem são os assexuais: relatos de brasileiros que não se interessam por sexo. Vinicius Lemos, Cuiabá, 2018. Disponível em: https://www.bbc.com/portuguese/geral-45634242. Acesso em: 3 nov. 2020

BOGAERT, Anthony. Asexuality and Autochorissexualism (Identity-Less Sexuality). Archives of sexual behavior. 2012 
BORgognA, N. C., et al. Anxiety and Depression Across Gender and Sexual Minorities: Implications for Transgender, Gender Nonconforming, Pansexual, Demisexual, Asexual, Queer, and Questioning Individuals. 2018

BUTLER. Judith. Problemas de Gênero: feminismo e subversão da identidade. $4^{\underline{a}}$ edição. Rio de Janeiro, RJ: Civilização Brasileira, 2012.

CARRIGAN, M. How Do You Know You Don't Like It If You Haven't Tried It? Asexual Agency and the Sexual Assumption'. In T.G. Morrison, M.A. Morrison, M. Carrigan and D. T. McDermott (Eds.) Sexual Minority Research in the New Millennium. Hauppauge, NY: Nova Science, 2012.

CARRIGAN, M. There's more to life than sex? Difference and commonality within the asexual community. Sexualities, 201 .

CROOKS, Robert L.; BAUR, Karla. Our Sexuality. 13. ed. atual. Boston: Cengage Learning, 2016.

CHAUÍ, Marilena de Souza. Repressão Sexual essa nossa (des)conhecida. 9 Ed. Brasiliense. São Paulo, 1984 .

FOUCAULT, Michel. História da sexualidade I: a vontade de saber. Tradução Maria Thereza da Costa Albuquerque e J. A. Guilhon Albuquerque. Rio de Janeiro/São Paulo: Paz \& Terra, 2014

GAZZOLA, S. B.; MORRISON, M. A. “Asexuality: An emergent sexual orientation”. In Sexual minority research in the new millennium, New York, NY: Nova Science, 2012.

GIL, Antonio Carlos. Como elaborar projetos de pesquisa. 4. ed. rev. São Paulo: Atlas S.A, 2002. 8176 p. v. 7 .

GRAY, David E. Pesquisa no mundo real. 2. ed. atual. São Paulo: ARTMED S.A, 2012. 7-245 p.a

HINDERLITER, A. How is asexuality different from hypoactive sexual desire disorder? Psychology \& Sexuality, 2013

MARCONI, Marina de Andrade; LAKATOS, Eva Maria. Fundamentos da metodologia científica. 5. ed. atual. São Paulo: Atlas, 2003. 7-310 p.

NEIVA, Giórgiade Aquino. "Já experimentou para saber se gosta?": assexualidades na sociedade sexualizada. Orientador: Camilo Albuquerque de Braz. 2015. Tese (Doutorado em antropologia social) - UNIVERSIDADE FEDERAL DE GOIÁSFACULDADE DE CIÊNCIAS SOCIAIS, Goiânia, 2019. Disponível em: https://files.cercomp.ufg.br/weby/up/r88/o/2015__Gi\%C3\%B3rgia_\%28D\%29.pdf. Acesso em: 2 out. 2020.

OLIVEIRA, Elisabete R. B. Assexualidade e medicalização na mídia televisiva norte-americana In: VIEIRA. T. R. (org)Minorias Sexuais: direitos e preconceitos. ed. Brasília : Editora Consultex, 2012

PRAUSE, N.; GRAHAM, C. A. Asexuality: Classification and characterization. Archives of Sexual Behavior, 2007.

Rozenthal, Eduardo. Assexualidade: um olhar psicanalítico para o futuro. Cad. Psicanál. (CPRJ), Rio de Janeiro, v. 40, n. 38, p. III-I24, 20I8. Disponível em: http://pepsic.bvsalud.org/pdf/cadpsi/v4on38/v40n38a07.pdf. Acesso em: 03 nov. 2020 
SORIA, Lucía. Asexualidad: primeras aproximaciones, primeros interrogantes. V Congreso Internacional de Investigación y Práctica Profesional en Psicología XX Jornadas de Investigación Noveno Encuentro de Investigadores en Psicología del MERCOSUR. Facultad de Psicología Universidad de Buenos Aires, Buenos Aires. 2013.

SANTOS, Valéria Konk dos. (AS)sexualidades: Processo de subjetivação e Resistência. Orientador: Suely Belinha Rolnik. 2016. 8I f. Dissertação (Mestrado em Psicologia Clínica) - Universidade Católica de São Paulo, São Paulo, 2015. Disponível em: https://tedez.pucsp.br/handle/handle/19428. Acesso em: 14 jun. 2020.

SCHERRER, K. S. Chegando a uma identidade assexual: negociar identidade, negociar desejo. Sexualidades, II, 2008.

SCOTT, Susie \& DAWSON, Matt. Rethinking asexuality: a simbolic interacionist account. Sexualities, n. I-2, I8: p. 3-19, fev. 2015

WITTIG, Monique. El Pensamiento Heterosexualy Otros Ensayos. Beacon Press, Boston, 1992. 